\title{
Cellulose Nanocrystals and Jute Fiber-reinforced Natural Rubber Composites: Cure Characteristics and Mechanical Properties
}

\author{
Carla Almeda Correia $^{a}{ }^{\circledR}$, Ticiane Sanches Valera ${ }^{a *}$
}

\author{
${ }^{a}$ Departamento de Engenharia Metalúrgica e de Materiais, Escola Politécnica, Universidade de São Paulo, \\ São Paulo, SP, Brasil
}

Received: February 22, 2019; Revised: May 10, 2019; Accepted: June 02, 2019

\begin{abstract}
A comparative study was conducted for three natural rubber (NR) composites: one containing raw jute fibers, one containing bleached jute fibers, and one containing cellulose nanocrystals (CNCs). The composites were prepared by adding each filler at 5 or $10 \mathrm{phr}$ to the latex before chemical coagulation, and the composites were processed in a two-roll mixing mill. The mechanical, thermal, and vulcanization properties of the prepared composites were then determined. The NR stiffness increased with increasing fiber content, particularly when bleached fibers were added, as evidenced by the increased elastic moduli, maximum torques, glass transition temperature, and crosslinking density. Scanning electron microscopy showed agglomerates in the composite with $10 \mathrm{phr}$ CNCs, which led to poorer mechanical performance compared to that of the bleached fiber-reinforced composite (10 phr). On the other hand, the addition of CNCs to the NR increased the cure rate index, thereby significantly advancing the optimum vulcanization time.
\end{abstract}

Keywords: Natural rubber, jute fibers, cellulose nanocrystals, mechanical properties, crosslink density.

\section{Introduction}

Natural rubber (NR) is the only elastomer that is extracted from a renewable source (Hevea brasiliensis) ${ }^{1}$. It is an important elastomer, with interesting properties compared to synthetic rubbers, such as high mechanical strength, elasticity, flexibility, resilience, and abrasion resistance ${ }^{2,3}$. However, these properties are obtained after vulcanization, during which crosslinks are formed between the polymer chains ${ }^{4}$, generally using sulfur as the vulcanizing agent. The mechanical properties of NR can also be improved and adjusted by adding reinforcing fillers.

To develop sustainable composite materials ${ }^{5}$, fillers extracted from renewable sources, such as natural fibers, can be used ${ }^{6}$. These have several advantages over commercial synthetic fillers ${ }^{7,8}$ (low cost, biodegradability, and attractive mechanical properties such as tensile strengths comparable to those of carbon and glass fibers). Jute fiber is a low-cost commercially available natural fiber; it is abundant in nature and has a high cellulose content ${ }^{9,10}$. Studies ${ }^{9,11}$ have shown that the addition of jute fibers to NR helps improve the modulus of elasticity and hardness of NR. However, to apply lignocellulosic fibers as a reinforcement in polymeric composites, it is desirable to remove lignin and other amorphous materials from these fibers, mainly to allow the separation of their fibrils ${ }^{10,12}$. The most common procedures for this include mercerization using a sodium hydroxide solution ${ }^{8,12}$ and bleaching using sodium chlorite $^{13}$; these treatments can be applied together. Mercerized and/or bleached fibers can be applied as a reinforcement for different types of polymer matrices ${ }^{14-16}$, thus increasing the modulus of elasticity by at least $20 \%$.

*e-mail: tsvalera@usp.br
Studies are actively being conducted on the extraction of crystalline regions of cellulose, forming nanometric particles, also called cellulose nanocrystals $(\mathrm{CNCs})^{5}$, which have a high surface area associated with good mechanical properties, low density, and biodegradability ${ }^{13,17}$. The addition of CNCs can help increase the tensile strength and elastic modulus of vulcanized $\mathrm{NR}$; however, this drastically decreases the elongation ${ }^{4,18}$. Few studies ${ }^{17,19}$ analyzed the vulcanization process of NR with the addition of CNCs and reported increased crosslink density.

In this work, three NR composites, one containing raw jute fibers, one containing bleached jute fibers, and one containing $\mathrm{CNCs}$, were prepared with different filler concentrations (5 and $10 \mathrm{phr}$ ). The tensile strength and hardness of the prepared composites were measured, and their morphology, vulcanization characteristics, and thermal behavior were then evaluated.

\section{Methods and Materials}

\subsection{Materials}

A centrifuged NR latex with $60 \%$ dry rubber and a high ammonia content was purchased from Du Latex (SP, Brazil); the latex is originally from Malaysia. Raw jute fibers were supplied by Castanhal Textile Company (PA, Brazil).

\subsection{Bleaching of jute fibers}

The bleaching procedure is in accordance with a previous work $^{20}$. The jute fibers were milled using a mechanical milling machine with a $0.5 \mathrm{~mm}$ sieve opening. The fibers $(30 \mathrm{~g})$ were dispersed in deionized water at $70{ }^{\circ} \mathrm{C}$ and stirred for $3 \mathrm{~h}$. 
The fiber bleaching procedure was based on the TAPPI T19m-54 standard method, as described by Trindade et al. ${ }^{21}$. After washing and filtering, the fibers were dispersed in deionized water at $70{ }^{\circ} \mathrm{C}$, and sodium chlorite $(25 \mathrm{~g})$ and glacial acetic acid $(10 \mathrm{~mL})$ were added to the aqueous suspension. The system was vigorously stirred for $1 \mathrm{~h}$. This procedure was repeated twice, i.e., sodium chlorite and glacial acetic acid were added again after a $1 \mathrm{~h}$ interval. After the final addition of the reagents, the system was stirred for $3 \mathrm{~h}$. The total reaction time was $5 \mathrm{~h}$. After washing and filtering, the fibers were treated with a $2 \% \mathrm{NaOH}(\mathrm{w} / \mathrm{w})$ solution, stirred at $80^{\circ} \mathrm{C}$ for $2 \mathrm{~h}$, filtered until a pH of 7 was obtained, and finally, dried in a vacuum oven at $60^{\circ} \mathrm{C}$ for at least $24 \mathrm{~h}$. For the subsequent preparation of the NR composites with bleached jute fibers, they were kept wet, and the dry fiber mass was calculated via three aliquots.

\subsection{Extraction of cellulose nanocrystals (CNCs)}

The CNCs were extracted by acid hydrolysis with sulfuric acid, and the reaction conditions were based on the most discussed parameters in literature ${ }^{22-24}$. Approximately $10 \mathrm{~g}$ of bleached jute fibers were dispersed in $200 \mathrm{ml}$ of $50 \%$ (w/w) sulfuric acid $\left(\mathrm{H}_{2} \mathrm{SO}_{4}\right)$. The mixture was continuously stirred at $300 \mathrm{rpm}$ for $75 \mathrm{~min}$ at $50^{\circ} \mathrm{C}$. The resulting suspension was cooled in an ice bath and diluted four times with deionized water. The neutralization step involved four centrifugation cycles at $15,000 \mathrm{rpm}$ and $10{ }^{\circ} \mathrm{C}$ for $5 \mathrm{~min}$, with the addition of deionized water. Thereafter, the resulting suspension was subjected to dialysis using a semipermeable cellulose membrane in deionized water until the $\mathrm{pH}$ of the suspension remained in the range of 6-7. Subsequently, the neutralized suspension was subjected to ultrasonication for $30 \mathrm{~min}$. Finally, the suspension was stored in a refrigerated form.

\subsection{Preparation of NR composites}

The NR composites were prepared by mixing an aqueous dispersion (approximately 2 wt.\%) of the different fillers (raw jute fibers, bleached fibers, and CNCs) with the NR latex (60 wt.\%) such that the filler concentrations reached the desired values ( 5 and $10 \mathrm{phr}$ ). The mixtures were then dispersed using an Ultra Turrax disperser (IKA) at 10,000 rpm for $5 \mathrm{~min}$. The mixtures were coagulated by adding a sufficient amount of acetic acid ( $3 \mathrm{~mol} / \mathrm{L})$ to small latex portions until the solidification of the rubber was complete. Next, the rubbers were immersed in deionized water for five days for neutralization, and the rubber was then oven dried for $72 \mathrm{~h}$ at $60^{\circ} \mathrm{C}$. The rubber mixtures were prepared in a laboratory two-roll mixing mill. First, the NR was masticated for $5 \mathrm{~min}$, and the components, listed in Table 1, were then added in the order presented, with a mixing time of $5 \mathrm{~min}$ for each material. The samples were vulcanized at $150{ }^{\circ} \mathrm{C}$ in a heated hydraulic press at $20 \mathrm{MPa}$ for their respective vulcanization times $\left(\mathrm{t}_{90}\right)$. The values were determined using an oscillating disc rheometer ODR 2000 (TEAM, Brazil) based on ASTM D-2084-11.
Table 1. Basic formulation of natural rubber composites.

\begin{tabular}{cc}
\hline Materials & Parts \\
\hline Natural rubber & 100 \\
Jute fibers (raw or bleached) & $0-10$ \\
CNCs & 1.5 \\
Plasticizing oil $^{\text {a }}$ & 1 \\
Antioxidant oil $^{\mathrm{b}}$ & 5 \\
Zinc Oxide $_{\text {Stearic acid }}$ & 2 \\
CBS $^{\mathrm{c}}$ & 0.8 \\
ZBEC $^{\mathrm{d}}$ & 0.15 \\
Sulfur & 2 \\
\hline
\end{tabular}

$\overline{\text { aParaffinic oil; }{ }^{\text {b }} \text { Styrene phenol;c N-cyclohexyl-2-benzothiazyl }}$ sulfenamide $;{ }^{\text {d }}$ Zinc dibenzyldithiocarbamate.

\subsection{Methods}

To observe the surface morphology of the raw jute fibers and bleached fibers, the samples were coated with a thin layer of conductive material (gold) and observed using a field-emission scanning electron microscope (FEI, INSPECT F50 SEM-FEG) at an applied accelerating voltage of $15 \mathrm{kV}$. The fiber diameter measurements were performed using Image J software, with at least fifty measures to obtain an average of the values. Subsequently, the NR composites were cryogenically fractured and analyzed using SEM-FEG with the same conditions previously mentioned.

The X-ray diffraction (XRD) analysis of the raw jute fibers, bleached fibers, and CNCs were performed in an XPERT-MPD diffractometer, with $\mathrm{Cu}-\mathrm{K} \alpha$ radiation $(\lambda=$ $1.544 \AA$ ). The scattered radiation was detected in a $2 \theta$ range of 5 to $40^{\circ}$ at a scanning rate of $0.02 \% \mathrm{~min}$. The samples were dried in a vacuum oven and powdered using a highenergy ball mill (attritor mill). The crystallinity index (CI) was estimated by subtracting the amorphous halo ${ }^{25}$ of the XRD curves by creating a baseline using the Origin 8.0 software. The CI was calculated using Equation 1, where CI expresses the relative degree of crystallinity, $A_{t}$ is the total area of the XRD curves, and $A_{c}$ is the sum of the peak areas corresponding to the crystalline structure of cellulose, calculated after the baseline correction.

$$
C I(\%)=\frac{A_{c}}{A_{t}} \times 100
$$

The CNC samples were observed in a transmission electron microscope (JEOL-1010). An acceleration voltage of $80 \mathrm{kV}$ was used. A drop of CNC aqueous suspension diluted to $0.4 \mathrm{mg} / \mathrm{ml}$ was deposited on a copper grid covered with a carbon film and dried in an oven for $2 \mathrm{~h}$ at $60{ }^{\circ} \mathrm{C}$. The diameter and length of the CNCs were measured using the Image J software with at least fifty measures.

The sample hardness was determined using a Shore A-type durometer. Compound samples (6-mm thick) were used to carry out the measurements. The tensile tests were 
performed based on the ASTM D412-15a standard on a universal testing machine (Kratos, DEK model) fitted with a contact-style extensometer. The crosshead speed was $500 \mathrm{~mm} / \mathrm{min}$, and a $500 \mathrm{~N}$ load cell was used.

A dynamic mechanical thermal analysis (DMTA) of the NR composites was performed on a DMTA instrument (DMA 8000, PerkinElmer) using rectangular samples with dimensions of $12 \mathrm{~mm} \times 10 \mathrm{~mm} \times 2.5 \mathrm{~mm}$. The experiment was carried out at a frequency of $1 \mathrm{~Hz}$, at temperatures ranging from -100 to $-12^{\circ} \mathrm{C}$, at a heating rate of $2{ }^{\circ} \mathrm{C} / \mathrm{min}$, and for an oscillation amplitude of $50 \mu \mathrm{m}$.

The crosslink density $(v)$ values were determined by swelling method using Equation $2^{26,27}$, where $M_{c}$ is the molecular weight between the crosslinks, which was calculated using Equation $3^{26,27}$, where $v_{n}$ is the molar volume of the solvent; $\rho_{p}$ is the density of the polymer; and $V_{r f}$ is the volume fraction of the rubber phase in the swollen gel of the rubber vulcanizate.

$$
\nu=\frac{1}{2 M_{c}}
$$

where

$$
M_{c}=\frac{-\rho_{p} \nu_{n} V_{r f}^{1 / 3}}{\left[\ln \left(1-V_{r f}\right)+V_{r f}+\chi V_{r f}^{2}\right]}
$$

$\chi$ is the interaction parameter between the polymer and the solvent and is expressed in Equation $4^{26,27}$, where $\beta$ is the lattice constant; $\delta_{p}$ and $\delta_{s}$ are the solubility parameters of the polymer and solvent, respectively; $R$ is the gas constant; and $T$ is the absolute temperature.

$$
\chi=\beta+\frac{\nu_{n}}{R T}\left(\delta_{s}-\delta_{p}\right)^{2}
$$

The volume fraction of the rubber phase in the swollen gel of the filled rubber vulcanizate $\left(V_{r}\right)$ was calculated by considering only the fraction of the rubber compounds, i.e., by subtracting the fiber amount using the empirical density of each filler, as described by Jacob et. al. ${ }^{28}$, using Equation 5 , where $d$ is the de-swollen weight of the sample; $f$ is the volume fraction of the fiber; $w$ is the initial weight of the sample, $\rho_{s}$ is the density of the solvent, and $A_{s}$ is the amount of solvent absorbed by the sample.

$$
V_{r f}=\frac{(d-f w) \rho_{p}^{-1}}{(d-f w) \rho_{p}^{-1}+A_{s} \rho_{S}^{-1}}
$$

The swelling of the NR composites was carried out in toluene for $72 \mathrm{~h}$ at room temperature, using square samples with a width of $10 \mathrm{~mm}$ and a thickness of $2 \mathrm{~mm}$.

\section{Results and Discussion}

\subsection{Fiber characterization}

Figure 1 shows the SEM images of the jute fibers before and after the bleaching process. The surfaces of the bleached fibers are softer and more uniform with fewer solid aggregates. In addition, the bleached fibers have a structure with individual microfibrils and are more dispersed than the raw fibers; this may indicate that the treatment was able to remove a significant amount of amorphous mass lying between the surfaces of the microfibrils, such as lignin, impurities, and low molar mass polysaccharides ${ }^{29}$.

Figure 2 shows the TEM image obtained from the CNCs, which presents individual nanocrystals with a fine needle-like shape. These particles exhibit a certain agglomeration, which may be due to the drying process during the preparation analysis. The average diameter and length of the CNCs were measured. Table 2 lists the results. A comparison of the results shows that, as expected, the acid hydrolysis process helped reduce the size of the fibers, reaching an average diameter of $16 \pm 4 \mathrm{~nm}$ and a length of $414 \pm 72 \mathrm{~nm}$, consistent with those reported in literature for cellulose nanocrystals ${ }^{30,31}$.

Figure 3 shows the XRD curves for the jute fibers before and after the bleaching treatment and for the CNCs. The highest intensity peak at approximately $2 \theta=22.3^{\circ}$ and the lowest intensity diffraction peaks at $2 \theta=15.8^{\circ}$ and $2 \theta=34.5^{\circ}$, which was more pronounced for $\mathrm{CNCs}$, indicated the presence of type I cellulose, and were assigned to plane (200), overlapping of (11̄0)/(110), and (004) crystallographic planes, respectively ${ }^{22,23}$. The increase in the peak intensity after the bleaching and acid hydrolysis of the jute fibers indicates an increase in the crystallinity after applying the treatments. The crystallinity indices for the raw jute fibers, bleached fibers, and CNCs were 56, 59, and 75\%, respectively, indicating an increase in the crystallinity of the jute fibers after the bleaching process and a further increase after acid hydrolysis, which indicates the removal of amorphous regions by the treatments performed ${ }^{19}$.

\subsection{Composite characterization}

\subsubsection{Cure characteristics}

Figure 4 shows the rheometric curves of the NR composites. Table 3 lists the curing characteristics of the NR composites, expressed in terms of the maximum and minimum torques $\left(\mathrm{M}_{\mathrm{H}}\right.$ and $\mathrm{M}_{\mathrm{L}}$, respectively), scorch time $\left(\mathrm{ts}_{2}\right)$, optimum cure time $\left(\mathrm{t}_{90}\right)$, delta torque $(\Delta \mathrm{M})$, and cure rate index (CRI).

The addition of the fibers to the NR increased the maximum torque values of the composites. A comparison of the composites with the same filler content shows that the effect was more pronounced in composites with bleached jute fibers. This indicates an increase in the stiffness of the vulcanized composites because of the restriction in the mobility of the rubber chains due to the addition of fibers ${ }^{32}$. For composites with raw and bleached jute fibers, there was no significant difference in the minimum torque compared to pure NR. The addition of these fibers did not hinder the processing of the NR in the two-roll mixing mill. In the case of the addition of the $\mathrm{CNCs}$, there was a slight decrease 

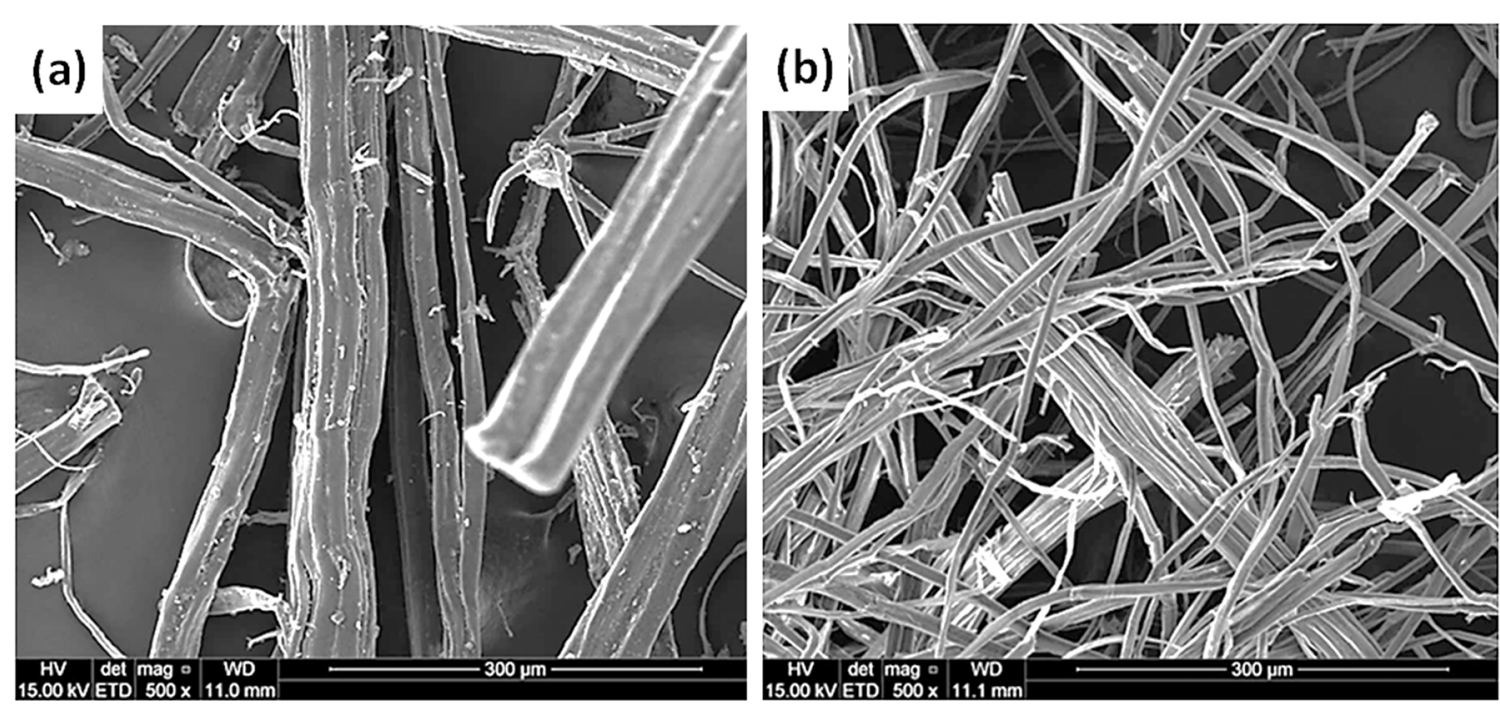

Figure 1. SEM micrographs $(\times 500)$ of (a) raw and (b) bleached jute fibers.

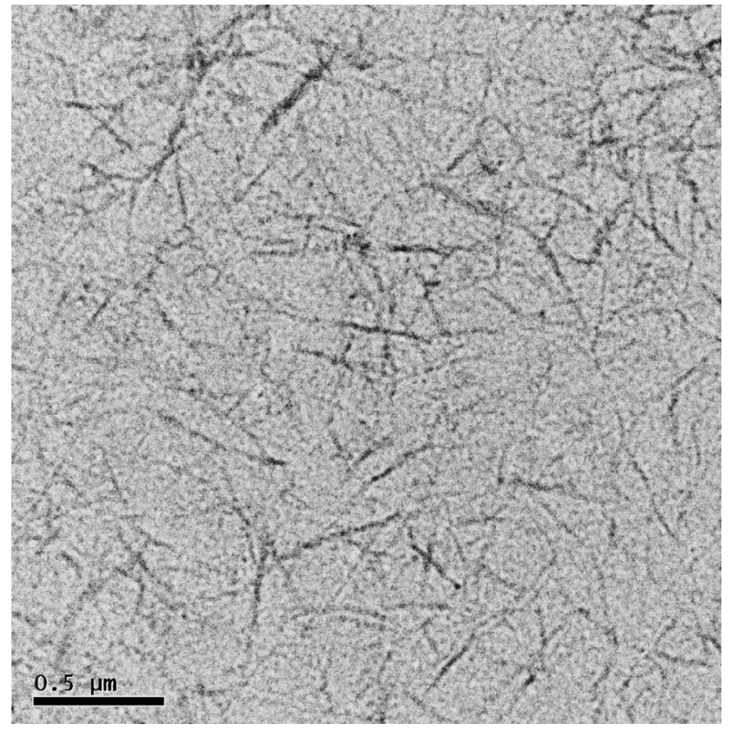

Figure 2. TEM image of dried dispersion of CNCs.

Table 2. Diameter, length, and aspect ratio for raw jute fibers (JF), bleached jute fibers (BJF), and CNCs.

\begin{tabular}{cccc}
\hline Sample & Diameter & Length $(\mathrm{nm})$ & Aspect Ratio \\
\hline $\mathrm{FJ}^{*}$ & $22 \pm 10 \mu \mathrm{m}$ & - & - \\
$\mathrm{BJF}^{*}$ & $7 \pm 2 \mu \mathrm{m}$ & - & - \\
$\mathrm{CNC}$ & $16 \pm 4 \mathrm{~nm}$ & $414 \pm 72$ & $26 \pm 6$ \\
\hline
\end{tabular}

"measured from SEM images

in $M_{L}$. This may indicate that the $\mathrm{CNCs}$ decreased the viscosity of the NR, favoring its processing in the two-roll mixing mill.

The addition of raw and bleached fibers to the NR reduced the optimum cure time of the composites when compared to the $\mathrm{NR}$, and a higher reduction in $\mathrm{t}_{90}$ and therefore a higher cure rate index was observed for the NR composites containing CNCs.

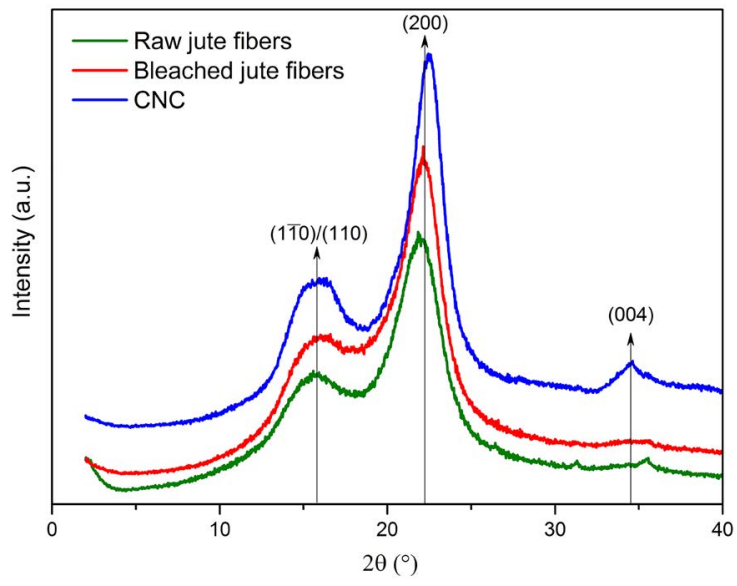

Figure 3. X-ray diffraction curves for raw, bleached jute fibers, and CNCs.

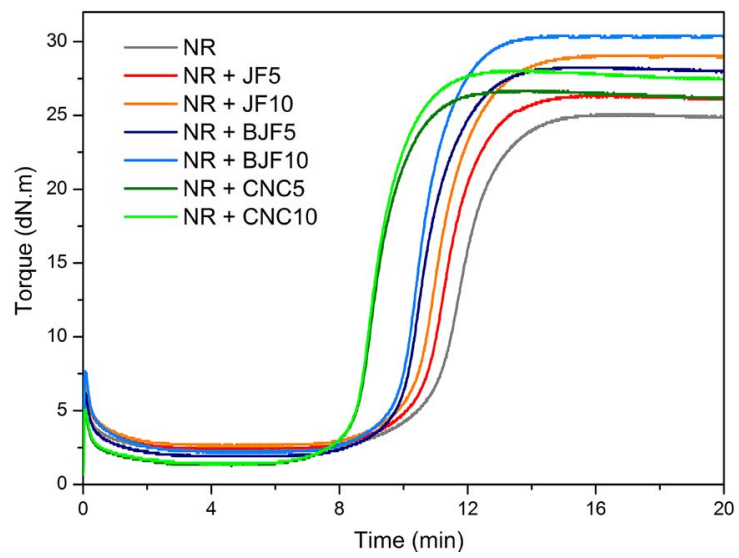

Figure 4. Rheometric curves for the three NR composites containing raw jute fibers (JF), bleached jute fibers (BJF), and CNCs. 
Table 3. Vulcanizing behavior of NR and NR composites at $150{ }^{\circ} \mathrm{C}$

\begin{tabular}{ccccccc}
\hline Sample & $\mathrm{M}_{\mathrm{L}}(\mathrm{dN} \cdot \mathrm{m})$ & $\mathrm{M}_{\mathrm{H}}(\mathrm{dN} . \mathrm{m})$ & $\mathrm{ts}_{2}(\mathrm{~min})$ & $\mathrm{t}_{90}(\mathrm{~min})$ & $\Delta \boldsymbol{M}^{*}(\mathrm{dN} \cdot \mathrm{m})$ & $\mathrm{CRI}^{* *}\left(\mathrm{~min}^{-1}\right)$ \\
\hline NR & 2.3 & 25.1 & 10.16 & 13.33 & 22.8 & 31.6 \\
NR + JF 5 & 2.4 & 26.3 & 9.92 & 12.83 & 23.9 & 34.4 \\
NR + JF 10 & 2.6 & 29.0 & 9.73 & 12.80 & 26.4 & 32.6 \\
NR + BJF 5 & 1.9 & 28.2 & 9.43 & 12.27 & 26.3 & 35.2 \\
NR + BJF 10 & 2.1 & 30.4 & 9.34 & 11.98 & 28.3 & 37.9 \\
NR + CNC 5 & 1.2 & 26.7 & 8.19 & 10.60 & 25.5 & 41.5 \\
NR + CNC 10 & 1.4 & 28.0 & 8.22 & 10.62 & 26.6 & 41.7 \\
\hline
\end{tabular}

$* \Delta M=M_{H}-M_{L}$

$* * \mathrm{CRI}=$ Cure rate index $=100 /\left(\mathrm{t}_{90}-\mathrm{ts}_{2}\right)$

Other studies ${ }^{32,33}$ have reported similar results for composites based on NR and natural fibers. However, for NR composites containing $\mathrm{CNCs}$, a study ${ }^{17}$ showed that the addition of CNCs can cause a delay in the vulcanization time, as $\mathrm{CNCs}$ have acidic groups on their surface ${ }^{34}$ (when obtained by acid hydrolysis with $\mathrm{H}_{2} \mathrm{SO}_{4}$ ), which do not favor the vulcanization reaction ${ }^{17}$. In contrast, in the case of this work, the addition of the fibers, particularly those that were chemically treated, favored the vulcanization reaction. In fact, Thomas et $\mathrm{al}^{19}$ showed that cellulose can form a chemical structure with zinc from $\mathrm{ZnO}$, contributing to the formation of the crosslinked network. Thus, the smaller size of the CNCs and consequently the larger surface area, compared with the other fillers, may have contributed to the further decrease in $\mathrm{t}_{90}$ of the NR composites.

\subsubsection{Hardness}

Table 4 lists the hardness values of the NR composites. As expected, the hardness of the composites increased with the increase in the fiber content. Studies ${ }^{11,35}$ reported that the addition of fibers helps in significantly increasing the hardness of NR composites. This effect was more pronounced in composites with bleached fibers. For the composites containing $\mathrm{CNCs}$, the addition of this filler caused a slight increase in the hardness, consistent with other composites based on rubber and nanometric fillers ${ }^{36}$.

\subsubsection{Tensile strength}

Table 4 lists the mechanical properties of the NR composites. A slight reduction in the tensile strength values and elongation at break with the addition of fillers was observed. Other works ${ }^{11,32}$ reported a similar behavior when natural fibers were added to NR, whereas the addition of $\mathrm{CNCs}^{4,37}$ led to an increase in the tensile strength with a significant reduction in the elongation.

In this work, only the elastic modulus at 100 and $300 \%$ elongation $\left(\mathrm{M}_{100}\right.$ and $\left.\mathrm{M}_{300}\right)$ increased with the addition of fibers and CNCs, compared to pure NR. This behavior was more pronounced in the case of bleached jute fibers. This effect is similar to that reported by other authors ${ }^{11,19,33}$, who concluded that the use of natural fibers as a reinforcement in NR matrices leads to an increase in the modulus of elasticity because of the strong interactions between the surface of the fibers and the matrix.

\subsubsection{Dynamic mechanical thermal analysis (DMTA)}

The glass transition temperature $\left(T_{g}\right)$ of the NR composites was determined using the tan delta peak position (Table 5). The addition of fibers to the NR slightly increased the $T_{g}$ values, which can be related to the restriction imposed by the fibers or CNCs on the mobility of the polymer chains.

Table 4. Mechanical properties of NR and NR composites.

\begin{tabular}{cccccc}
\hline Sample & $\begin{array}{c}\text { Tensile Strength } \\
(\mathrm{MPa})\end{array}$ & $\begin{array}{c}\text { Elongation at break } \\
(\%)\end{array}$ & $\mathrm{M}_{100}(\mathrm{MPa})$ & $\mathrm{M}_{300}(\mathrm{MPa})$ & Hardness (Shore-A) \\
\hline NR & $22.3 \pm 0.8$ & $687 \pm 12$ & $0.78 \pm 0.02$ & $1.82 \pm 0.04$ & $34.4 \pm 0.3$ \\
NR + JF5 & $21.0 \pm 0.7$ & $640 \pm 22$ & $1.06 \pm 0.04$ & $2.18 \pm 0.09$ & $38.2 \pm 0.1$ \\
NR + JF10 & $20.1 \pm 0.5$ & $618 \pm 25$ & $1.25 \pm 0.03$ & $2.47 \pm 0.07$ & $41.6 \pm 0.3$ \\
NR + BJF5 & $20.2 \pm 1.1$ & $649 \pm 28$ & $1.41 \pm 0.07$ & $2.55 \pm 0.09$ & $39.3 \pm 0.4$ \\
NR + BJF10 & $20.5 \pm 0.8$ & $653 \pm 19$ & $2.12 \pm 0.06$ & $3.42 \pm 0.05$ & $47.8 \pm 0.2$ \\
NR + CNC5 & $21.8 \pm 0.7$ & $649 \pm 14$ & $0.92 \pm 0.02$ & $2.63 \pm 0.08$ & $36.4 \pm 0.4$ \\
NR + CNC10 & $21.3 \pm 0.7$ & $652 \pm 10$ & $0.98 \pm 0.01$ & $2.51 \pm 0.05$ & $37.1 \pm 0.3$ \\
\hline
\end{tabular}


Table 5. Glass transition temperature of the NR and NR composites.

\begin{tabular}{cc}
\hline Sample & $\tan$ delta $\left({ }^{\circ} \mathrm{C}\right)$ \\
\hline NR & -50 \\
NR + JF5 & -48 \\
NR + JF10 & -49 \\
NR + BJF5 & -49 \\
NR + BJF10 & -48 \\
NR + CNC5 & -48 \\
NR + CNC10 & -48 \\
\hline
\end{tabular}

Table 6. Volume fraction of the rubber phase in the swollen gel of the rubber vulcanizate $\left(\mathrm{V}_{\mathrm{rr}}\right)$ and crosslinking density of the NR and NR composites.

\begin{tabular}{ccc}
\hline Sample & $\boldsymbol{V}_{r f}$ & $\begin{array}{c}\text { Crosslink density } \\
\times 10^{-5}\left(\mathrm{gmol} / \mathrm{cm}^{3}\right)\end{array}$ \\
\hline NR & 0.2003 & 4.16 \\
$\mathrm{NR}+\mathrm{JF5}$ & 0.1978 & 4.04 \\
$\mathrm{NR}+\mathrm{JF} 10$ & 0.1980 & 4.05 \\
$\mathrm{NR}+\mathrm{BJF5}$ & 0.2015 & 4.22 \\
$\mathrm{NR}+\mathrm{BJF10}$ & 0.2070 & 4.51 \\
$\mathrm{NR}+\mathrm{CNC5}$ & 0.2051 & 4.41 \\
$\mathrm{NR}+\mathrm{CNC10}$ & 0.2108 & 4.72 \\
\hline
\end{tabular}

\subsubsection{Crosslink Density}

Table 6 lists the values of the volume fraction of the rubber phase in the swollen gel of the filled rubber vulcanizate $\left(V_{r f}\right)$ and the crosslink density of the NR composites. The crosslink density slightly decreased with the addition of raw jute fibers to the NR. On the other hand, the addition of bleached fibers and CNCs to the NR increased the values of $V_{r p}$ and consequently, the crosslink density. According to a study ${ }^{28}$, as the amount of filler added to the NR increases, the amount of solvent absorbed by the sample decreases, thus increasing the $V_{r f}$ values and in turn increasing the crosslink density. Other authors ${ }^{17,26,38}$ reported similar results for rubber matrix composites and attributed this behavior to the interfacial interaction between the matrix and the filler ${ }^{17,19}$. Strong matrix-filler interactions can hinder solvent permeation in the rubber matrix, reducing the volume of the solvent absorbed after the swelling test ${ }^{17}$. The increase in the stiffness of the NR with the addition of fibers or CNCs (confirmed by the increase in the elastic modulus), the increase in the glass transition temperature, and the increase in the maximum torque can be attributed to the reduction in the mobility of the rubber molecules. This behavior can be attributed to the strong matrix-filler interaction and increased crosslink density.

However, the increase in the stiffness of CNC-added samples is not as significant as that of the bleached fiberadded samples. In the former case, the reduction in the amount of solvent absorbed by the sample decreased not only because of the strong polymer-solvent interaction, but also because of the significant increase in the surface area of the fillers (variable not considered in the equations used), which further hindered the permeation of the solvent into the polymer, interfering with the obtained crosslink density value. Thus, the sample with CNCs may exhibit a high value of $V_{r f}$, but not necessarily a significantly high crosslink density. In contrast, for the bleached fiber composites, whose addition in NR does not cause such a significant increase in the surface area, the obtained crosslink density values may be more realistic.

\subsubsection{Morphology of NR composites}

Figure 5 shows the SEM images of the NR composites. The images obtained of pure NR and of the composites indicate the presence of microscale particles (white arrows), which are probably related to the vulcanization additives. The micrographs of the composites with raw and bleached fibers [Figures 5(b), (c), (d), and (e)] show individual fibers distributed in the NR matrix (black arrows). The NR composites with raw jute fibers exhibit larger fibers than the composites with bleached fibers, as observed in the fiber micrographs (see Figure 1). Some cavities are observed in the composites, probably because of the pullout of the fibers from the matrix during cryogenic fracture. In the composites added with $10 \mathrm{phr}$ of bleached jute fibers, the fibers appear to be more interconnected than those in the other composites. This morphology may explain the increase in the tensile strength and hardness values. In addition, the composites based on NR and jute fibers have a more homogeneous fiber dispersion in the matrix phase than that observed in other works based on rubber and natural fibers ${ }^{11,29}$.

In the images obtained using SEM of the NR composites containing $5 \mathrm{phr}$ of CNCs [Figures 5(f) and (h)], no agglomerates are present. Conversely, in the composite with $10 \mathrm{phr}$ of CNCs, some clusters can be observed (black circles), consistent with other studies $\mathrm{s}^{4,17}$ on composites containing a high concentration of CNCs (above $10 \mathrm{phr}$ ). 

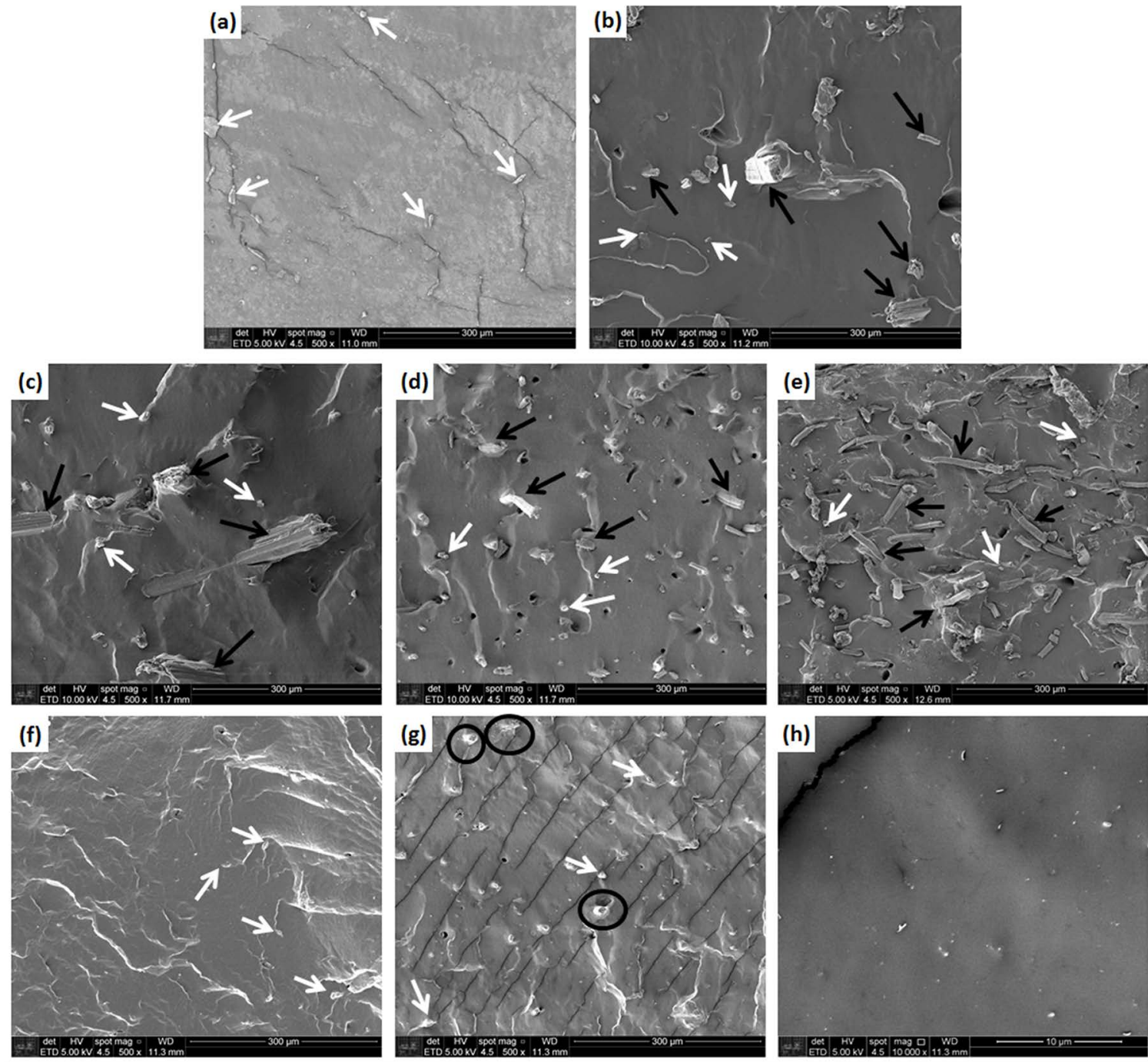

Figure 5. SEM images of (a) neat NR composite $(\times 500)$; NR composites with (b) 5 phr of raw jute fibers $(\times 500)$, (c) 10 phr of raw jute fibers $(\times 500)$, (d) 5 phr of bleached jute fibers $(\times 500)$, (e) $10 \mathrm{phr}$ of bleached jute fibers $(\times 500)$, (f) 5 phr of CNCs $(\times 500)$, (g) $10 \mathrm{phr}$ of $\mathrm{CNCs}(\times 500)$; and $(\mathrm{h})$ composite with $5 \mathrm{phr}$ of $\mathrm{CNCs}$ at higher magnification $(\times 10000)$.

\section{Conclusions}

The jute fiber bleaching process proved to be efficient, as the morphological analysis indicated that the treatment helped remove the solids from the surface of the fibers. The treatment also allowed the separation of microfibrils and the removal of amorphous mass from the fibers. Cellulose nanocrystals (CNCs) were obtained from the acid hydrolysis of bleached jute fibers. The XRD analysis of CNCs indicated an increase in the crystallinity index when compared to the raw and bleached jute fiber samples. TEM images showed the presence of thin needles, with dimensions consistent with those of cellulose nanocrystals. In relation to the composites, an increase in the stiffness of the NR matrix was observed with the addition of all three fillers (raw and bleached jute fibers and $\mathrm{CNCs}$ ).
A comparison of the properties of the different composites with those of pure NR compound showed that the maximum torque values, the modulus at 100 and $300 \%$ elongation, hardness, and $T_{g}$ values increased. In particular, the increases were more significant in the samples containing bleached fibers. These results are related to the reduction in the mobility of the rubber molecules due to the presence of the fillers. The samples containing bleached fibers and CNCs showed an increase in the $V_{r f}$ values, which can be attributed to the strong matrix-filler interaction and increased crosslink density. In addition, the rheometric results indicated that fibers, mainly bleached fibers and CNCs, favored the vulcanization reactions of the NR, significantly advancing the optimum vulcanization time, thereby increasing the cure rate index of the NR. 


\section{Acknowledgments}

The authors would like to thank Castanhal for providing the jute fibers, Proquitec for providing the antioxidant oil, Kratos Industrial Equipment for tensile analysis, and $\mathrm{CNPq}$ (Process No. 141817/2015-1) for the financial support. This study was financed in part by the Coordenação de Aperfeiçoamento de Pessoal de Nível Superior - Brasil (CAPES) - Finance Code 001 (Process No. 1671/18).

\section{References}

1. Phiriyawirut M, Chotirat N, Phromsiri S, Lohapaisarn I. Preparation and Properties of Natural Rubber - Cellulose Microfibril Nanocomposite Films. Advanced Materials Research. 2010;93-94:328-331.

2. Mariano M, El Kissi N, Dufresne A. Cellulose nanocrystal reinforced oxidized natural rubber nanocomposites. Carbohydrate Polymers. 2016;137:174-183.

3. Katzenberg F, Tiller JC. Shape memory natural rubber. Journal of Polymer Science Part B: Polymer Physics. 2016;54(14):1381-1388.

4. Visakh PM, Thomas S, Oksman K, Mathew AP. Crosslinked natural rubber nanocomposites reinforced with cellulose whiskers isolated from bamboo waste: Processing and mechanical/ thermal properties. Composites Part A: Applied Science and Manufacturing. 2012;43(4):735-741.

5. Julkapli NM, Bagheri S. Progress on nanocrystalline cellulose biocomposites. Reactive and Functional Polymers. 2017;112:9-21.

6. Adekomaya O, Jamiru T, Sadiku R, Huan Z. A review on the sustainability of natural fiber in matrix reinforcement - A practical perspective. Journal of Reinforced Plastics and Composites. 2016;35(1):3-7.

7. Sajithkumar KJ, Visakh PM, Ramasamy EV. Moringa oleifera (Drum Stick Vegetable Fibre) Based Nanocomposites with Natural Rubber: Preparation and Characterizations. Waste and Biomass Valorization. 2016;7(5):1227-1234.

8. Zhou Y, Fan M, Chen L. Interface and bonding mechanisms of plant fibre composites: An overview. Composites Part B: Engineering. 2016;101:31-45.

9. Khan RA, Khan MA, Zaman HU, Pervin S, Khan N, Sultana S, et al. Comparative Studies of Mechanical and Interfacial Properties Between Jute and E-Glass Fiber-Reinforced Polypropylene Composites. Journal of Reinforced Plastics and Composites. 2010;29(7):1078-1088.

10. Mohanty AK, Misra M, Drzal LT, Selke SE, Harte BR, Hinrichsen G. Natural Fibers, Biopolymers, and Biocomposites: An Introduction. In: Mohanty AK, Misra M, Drzal LT, eds. Natural Fibers, Biopolymers, and Biocomposites. Boca Raton: CRC Press; 2005.

11. Datta J, Wloch M. Preparation, morphology and properties of natural rubber composites filled with untreated short jute fibres. Polymer Bulletin. 2017;74(3):763-782.

12. Silva R, Haraguchi SK, Muniz EC, Rubira AF. Applications of lignocellulosic fibers in polymer chemistry and in composites. Química Nova. 2009;32(3):661-671.
13. Jain M, Pradhan MK. Morphology and mechanical properties of sisal fiber and nano cellulose green rubber composite: a comparative study. International Journal of Plastics Technology. 2016;20(2):378-400.

14. Han HC, Gong XL. One-step green treatment of hemp fiber used in polypropylene composites. Polymer Composites. 2016;37(2):385-390.

15. Somashekar S, Shanthakumar GC. Effect of Alkali Treatment on Mechanical Properties of Sisal-Reinforced Epoxy Polymer Matrix Composite. International Journal of Mechanical Engineering and Robotics Research. 2014;3(4):441-450.

16. Gunti R, Ratna Prasad AV, Gupta AVSSKS. Mechanical and degradation properties of natural fiber-reinforced PLA composites: Jute, sisal, and elephant grass. Polymer Composites. 2018;39(4):1125-1136.

17. Cao L, Fu X, Xu C, Yin S, Chen Y. High-performance natural rubber nanocomposites with marine biomass (tunicate cellulose). Cellulose. 2017;24(7):2849-2860.

18. McLauchlin AR, Thomas NL. Preparation and thermal characterisation of poly(lactic acid) nanocomposites prepared from organoclays based on an amphoteric surfactant. Polymer Degradation and Stability. 2009;94(5):868-872.

19. Thomas MG, Abraham E, Jyotishkumar P, Maria HJ, Pothen LA, Thomas S. Nanocelluloses from jute fibers and their nanocomposites with natural rubber: Preparation and characterization. International Journal of Biological Macromolecules. 2015;81:768-777.

20. Correia CA, de Oliveira LM, Valera TS. The Influence of Bleached Jute Fiber Filler on the Properties of Vulcanized Natural Rubber. Materials Research. 2017;20(Suppl 2):466-471.

21. Trindade WG, Hoareau W, Megiatto JD, Razera IAT, Castellan A, Frollini E. Thermoset Phenolic Matrices Reinforced with Unmodified and Surface-Grafted Furfuryl Alcohol Sugar Cane Bagasse and Curaua Fibers: Properties of Fibers and Composites. Biomacromolecules. 2005;6(5):2485-2496.

22. César NR, Pereira-da-Silva MA, Botaro VR, de Menezes AJ. Cellulose nanocrystals from natural fiber of the macrophyte Typha domingensis: extraction and characterization. Cellulose. 2015;22(1):449-460.

23. Kasyapi N, Chaudhary V, Bhowmick AK. Bionanowhiskers from jute: Preparation and characterization. Carbohydrate Polymers. 2013;92(2):1116-1123.

24. Revol JF, Godbout L, Dong XM, Gray DG, Chanzy H, Maret G. Chiral nematic suspensions of cellulose crystallites; phase separation and magnetic field orientation. Liquid Crystals. 1994;16(1):127-134.

25. Park S, Baker JO, Himmel ME, Parilla PA, Johnson DK. Cellulose crystallinity index: measurement techniques and their impact on interpreting cellulase performance. Biotechnology for Biofuels. 2010;3:10.

26. Mathew AP, Packirisamy S, Radusch HJ, Thomas S. Effect of initiating system, blend ratio and crosslink density on the mechanical properties and failure topography of nano-structured full-interpenetrating polymer networks from natural rubber and polystyrene. European Polymer Journal. 2001;37(9):1921-1934. 
27. Flory PJ, Rehner J Jr. Statistical Mechanics of Cross-Linked Polymer Networks I. Rubberlike Elasticity. The Journal of Chemical Physics. 1943;11(11):512-520.

28. Jacob M, Thomas S, Varughese KT. Mechanical properties of sisal/oil palm hybrid fiber reinforced natural rubber composites. Composites Science and Technology. 2004;64(7-8):955-965.

29. Cai M, Takagi H, Nakagaito AN, Li Y, Waterhouse GIN. Effect of alkali treatment on interfacial bonding in abaca fiberreinforced composites. Composites Part A: Applied Science and Manufacturing. 2016;90:589-597.

30. Brito BSL, Pereira FV, Putaux JL, Jean B. Preparation, morphology and structure of cellulose nanocrystals from bamboo fibers. Cellulose. 2012;19(5):1527-1536.

31. Flauzino Neto WP, Mariano M, da Silva ISV, Silvério HA, Putaux JL, Otaguro H, et al. Mechanical properties of natural rubber nanocomposites reinforced with high aspect ratio cellulose nanocrystals isolated from soy hulls. Carbohydrate Polymers. 2016;153:143-152.

32. Lopattananon N, Panawarangkul K, Sahakaro K, Ellis B. Performance of pineapple leaf fiber-natural rubber composites: The effect of fiber surface treatments. Journal of Applied Polymer Science. 2006;102(2):1974-1984.
33. De D, De D, Adhikari B. The effect of grass fiber filler on curing characteristics and mechanical properties of natural rubber. Polymers for Advanced Technologies. 2004;15(12):708-715.

34. Mariano M, El Kissi N, Dufresne A. Cellulose nanocrystals and related nanocomposites: Review of some properties and challenges. Journal of Polymer Science Part B: Polymer Physics. 2014;52(12):791-806.

35. Pittayavinai P, Thanawan S, Amornsakchai T. Manipulation of mechanical properties of short pineapple leaf fiber reinforced natural rubber composites through variations in cross-link density and carbon black loading. Polymer Testing. 2016;54:84-89.

36. Chen WJ, Gu J, Xu SH. Exploring nanocrystalline cellulose as a green alternative of carbon black in natural rubber/butadiene rubber/styrene-butadiene rubber blends. eXPRESS Polymer Letters. 2014;8(9):659-668.

37. Kato H, Nakatsubo F, Abe K, Yano H. Crosslinking via sulfur vulcanization of natural rubber and cellulose nanofibers incorporating unsaturated fatty acids. RSC Advances. 2015;5(38):29814-29819.

38. Arroyo M, López-Manchado MA, Herrero B. Organomontmorillonite as substitute of carbon black in natural rubber compounds. Polymer. 2003;44(8):2447-2453. 